\title{
A UTILIZAÇÃO DA LAVADORA DE LOUÇA INDUSTRIAL: UMA ALTERNATIVA PARA A CENTRAL DE MATERIAL E ESTERILIZAÇÃO*
}

\author{
Yukie Yokoyama** \\ Shizue Nakane** \\ Elaine Reganin*** \\ Ana Lúcia Queiroz Bezerra****
}

RESUMO: Neste estudo as autoras relatam a experiência desenvolvida na Central de Material e Esterilização de um hospital de grande porte da cidade de São Paulo, na utilização de uma máquina lavadora de louça de uso industrial, readaptada com temperatura ideal para o processo de lavagem de instrumental. $O$ estudo apresenta uma forma altemativa de trabalho com diminuição do tempo para operacionalização do serviço e menor exposição do pessoal aos resíduos orgânicos.

ABSTRACT: This work is being developed at the material and sterilization center of a large hospital in São Paulo city. The authors relates the use of a industrial dish washing machine adapted with a correct temperature for washing surgical instrumental. The study shows a non expensive altemative form to work, which diminishes time and personal exposure to the organic disposal.

\section{UNITERMOS: Limpeza - Sanitização - Riscos Ocupacionais - Central de Material Esterelizado.}

\section{INTRODUÇÃO}

Consideramos a Central de Material e Esterilização (CME) um dos mais importantes locais do contexto hospitalar, tanto do ponto de vista econômico como técnico administrativo, devido à sua grande abrangência. Qualquer procedimento realizado no paciente, poderá obter ou não sucesso, entre outros fatores, em função da qualidade do material utilizado.

Todo o processamento dos artigos médico-hospitalares nas instituições de saúde, desde a limpeza, seleção, acondicionamento, esterilização, guarda, distribuição e controle é de responsabilidade da CME.

Esta unidade é composta por diversas áreas, entre elas a de Expurgo, destinada ao recebimento e limpeza dos artigos sujos e/ou contaminados, provenientes do Centro Cinúrgico e de outras unidades do hospital.
A limpeza é a primeira e mais importante etapa, para que se atinja a eficácia dos procedimentos de desinfecção ou esterilização dos artigos.

Em publicações sobre o assunto, o processo de limpeza é definido como a remoção física de sujidades, realizada com água, adicionando, ou não, sabão ou detergente, de forma manual ou por ação mecânica ${ }^{(4)}$.

A limpeza manual ainda é o processo mais utilizado no nosso meio e consiste na lavagem dos instrumentos individualmente, sob água corrente, solução detergente e auxílio de escovas com cerdas de nylon.

Para a limpeza mecânica utiliza-se equipamentos como a lavadora-esterilizadora ou a lavadora ultrassônica, que possibilitam a descontaminação e/ou sanitização dos artigos médico hospitalares ${ }^{(3)}$.

A eficiência destes equipamentos depende da sua

\footnotetext{
* Trabalho apresentado como Tema Livre no $45^{\circ}$ Congresso Brasileiro de Enfermagem. Olinda-Recife - PE, 28 de novembro a 3 de dezembro de 1993

* Enfermeiras Supervisoras do Centro Cirúrgico e Central de Material do Hospital da Beneficência Portuguesa de Săo Paulo.

** Enfermeira da Central de Material e Esterilização do Hospital da Beneficência Portuguesa de São Paulo.

**** Enfermeira Supervisora do Setor de Educação em Serviço do Hospital da Beneficência Portuguesa de São Paulo.
} 
utilização adequada, que inclui a adoção das normas dos fabricantes, até o posicionamento dos materiais no seu compartimento interno.

Quanto à descontaminação através da lavadora ultrassônica é discutível, pois a temperatura e o tempo utilizados na exposição dos artigos não são suficientes para a destruição de microorganismos ${ }^{(5)}$.

$\mathrm{O}$ primeiro equipamento utilizado para lavagem de artigos médico-hospitalares foi descrito por Walter em 1938, uma autoclave vertical, onde se utilizava um recipiente de aço inox perfurado para colocação de material sujo. A cesta era colocada no aparelho que através de movimentos bruscos favorecia a penetração da água no aparelho e no cesto de instrumental. Um filtro de vapor ao fundo da câmara fornecia calor para a esterilização e produzia a convecção. A adição de detergente adequado, auxiliava a peptonizar proteínas e saponizar graxas $(5)$.

$\mathrm{O}$ avanço tecnológico vem proporcionando o aparecimento de muitos equipamentos no mercado nacional e especialmente internacional.

Para acompanhar essa evolução novos produtos e técnicas de limpeza são desenvolvidas. Tudo isso tem acarretado constantes adaptações no processo de limpeza de artigos médico-hospitalares. Porém esses equipamentos são de alto custo e nem sempre acessíveis às condições econômicas de algurnas instituições de saúde, levando o pessoal envolvido nessas atividades a buscar soluções altemativas para desenvolvimento do serviço, sem entretanto prejudicar a sua qualidade.

Desenvolvemos as nossas atividades profissionais como enfermeiras numa Central de Material e Esterilização de um hospital de grande porte da cidade de São Paulo, que dispõe de 1300 leitos, com o movimento cinúrgico em tomo de 2080 cirurgias mensais, das quais 560 são cinurgias cardiológicas.

Para atender a essa demanda cirúrgica faz-se necessário a reutilização constante dos instrumentais cinúrgicos existentes. Entretanto isso não ocorria, e era freqüente $o$ atraso no atendimento do movimento das cinurgias programadas para 0 dia.

Observava-se que o maior tempo gasto no tratamento com os instrumentais era no seu processo de lavagem. Os equipamentos utilizados no nosso serviço eram as lavadoras ultrassônicas, que devido ao grande tempo de uso, já apresentavam alguns problemas de manutenção constante, de um tempo maior para realização do seu ciclo, além do ruído que proporcionava desconforto ao pessoal que alí trabalhava. Pelos motivos expostos, sentiu-se a necessidade da aquisição de novos equipamentos para lavagem dos artigos, especialmente os instrumentais cinúrgicos, visto que enf rentávamos diariamente problemas diversos com o atraso das cinurgias programadas.

Para tanto passamos a utilizar uma lavadora-sanitizadora de louça industrial, já utilizada há um ano pelo Serviço de Nutrição e Dietética, indicada para uso na CME pela Comissão de Controle de Inf ecção e Qualidade, responsável pela seleção e aquisição de equipamentos hospitalares.

Este equipamento é utilizado para lavagem e sanitização de artigos inox, como instrumentais cirúrgicos, vidros, plásticos e borrachas. No nosso serviço o seu uso é exclusivo para instrumentais, pelas necessidades já citadas anteriormente. A capacidade do cesto da lavadora é para 150 peças por vez. O tempo por ciclo é 4 minutos, sendo 180 segundos para lavagem, 10 segundo de pausa e 50 segundos para enxague. $\mathrm{O}$ seu funcionamento se processa por uma bomba centrífuga de alta pressão, com jatos rotativos que fazem com que a água circule numa temperatura de $90^{\circ} \mathrm{C}$. Para enxague, a água é impulsionada através de jatos superiores e inferiores numa temperatura de $95^{\circ} \mathrm{C}$, finalizando o ciclo( ${ }^{(6)}$.

A dificuldade apresentada por este equipamento diz respeito à eliminação total de sujidades e resíduos aderidas em alguns instrumentos. Para evitar que isto ocorra, faz-se necessário previamente, a imersão destes em uma solução enzimática, bacteriostática e biodegradável específica para digerir, dissolver e eliminar odores de sangue, pus, fezes e outros materiais orgânicos.

A utilização desta lavadora de louça industrial para lavagem de instrumentais cinúrgicos tem sido considerada vantajosa pelas enfermeiras da CME. Portanto, estas se propuseram a relatar suas experiências com os seguintes objetivos:

- validar o uso da lavadora de louça industrial como solução alternativa para dinamizar o processo de lavagem dos instrumentais cinúrgicos, atendendo às necessidades do serviço;

- proporcionar a diminuição dos riscos ocupacionais decorrentes da limpeza manual.

\section{MÉTODO}

No nosso serviço, o processo de limpeza do instrumental cirúrgico utilizado antes da implantação da lavadora de louça industrial era mecânico-manual com o auxílio de solução detergente e escovas de 
cerdas de nailon, sendo o maior volume de artigos lavados manualmente.

A partir de julho de 1991, com a instalação da primeira lavadora de louça, o processo de limpeza dos instrumentais cirúrgicos, continuou o mesmo, mais com redução significativa da parte manual.

O processo de limpeza dos instrumentais cirúrgicos é realizado imediatamente após o uso e obedece as seguintes etapas:

1. Os instrumentais utilizados nos procedimentos cirúrgicos são separados por espécie na sala de cirurgia, e encaminhados ao Expurgo da $\mathrm{CME}$ em carro de inox próprio, devidamente cobertos com campos.

2. O funcionário do Expurgo, devidamente paramentado com luvas de borracha e avental impermeável, recebe esses materiais, dispondo-os em pias próprias de acordo com a espécie.

3. Os instrumentais são colocados nos cestos plásticos vazados próprios da lavadora, que estão dentro de caixas de inox contendo a solução enzimática, bacteriostática e biodegradável. $\mathrm{O}$ total de instrumentos, 150 peças por cesto, são dispostos totalmente abertos para facilitar a remoção de sujidades agregadas às suas articulações, cremalheiras e ranhuras. O tempo de imersão das peças nesta solução é de 3 minutos, sendo este considerado suficiente para a remoção de materiais orgânicos agregados ao instrumental.

4. Passado esse tempo, o cesto é retirado e colocado na lavadora. Esta, que já está ligada, atinge imediatamente a temperatura de $90^{\circ} \mathrm{C}$, quando se inicia o seu ciclo. A duração do ciclo é de 4 minutos correspondendo a lavagem, pausa e enxagüe.

5. Desligada a lavadora, o cesto é retirado e feita a inspeção das peças, para se detectar resíduos de sujidades. Nesse momento procede-se à escovação manual de alguns instrumentos, especialmente os que contêm ranhuras, com a finalidade de garantir a ef etividade da limpeza. Passa-se em água corrente.
6. Após esta etapa, é procedida a secagem manual dos instrumentais, utilizando-se compressas ou toalhas macias.

7. Os instrumentais devidamente secos são colocados em caixas de inox e encaminhados para a sala de preparo.

Esse processo de limpeza mecânico-manual, do momento em que o instrumental chega ao Expurgo, até o seu encaminhamento para a sala de preparo leva 20 minutos. $O$ processo anteriormente utilizado durava 60 minutos.

\section{CONSIDERAÇÕES FINAIS}

Devido aos resultados obtidos com o uso da lavadora de louça já contamos com três delas no serviço.

Temos verificado que:

- houve diminuição do tempo de espera de uma intervenção cirúrgica para outra, pela maior rapidez na lavagem dos instrumentais;

- a operacionalização do processo de limpeza se tornou mais dinâmica, pois enquanto a máquina está lavando, o pessoal está preparando o próximo lote de instrumentais;

- houve redução dos riscos ocupacionais com materiais pérfuro-cortantes, devido à menor utilização da lavagem manual;

- a aceitação do equipamento pelo pessoal do setor foi boa, pela ausência de ruídos;

- a manutenção é menos onerosa, com tecnologia simples e disponibilidade de peças, no mercado.

Recomendamos a utilização desta lavadora de louça industrial como solução alternativa para o desenvolvimento do trabalho no Expurgo de uma Central de Material e Esterilização, visto que o resultado final alcançado é de melhor qualidade e menor tempo no processo de limpeza dos instrumentais cirúrgicos, como também por estarmos cumprindo uma das normas de precauções universais pela menor exposição do pessoal. 


\section{REFERÊNCIAS BIBLIOGRÁFICAS}

1. CASTRO, M.E. O centro cirúrgico e o que passa pelo seu interior. Máscaras e luvas, contínuo aperfeiçoamento de enfermeira cinúrgica, v.2, n.3, p.13-15, 1982.

2. FERRAZ, E.M. Manual de controle de infeç̧ão em cirurgia, p.287-288, 1982.

3. GARNER, S.S., FAVERO, M.S., CDC guideline for handwashing and hospital environmental control. 1985. To day's OR murse, v.8, n.4, p.26-37, 1986.

4. LACERDA, R.A., SILVA, A. Limpeza dos artigos médicohospitalares. Rev. Pau. Hosp., Såo Paulo, v.15, n.5 a 12, $\mathrm{mai} / \mathrm{dez}, 1992$.
5. PERKINS, I.I. Principles and methods of sterilization in health sciences. Charles Thomas Publisher. 1980. cap.10 e 15.

6. SEMCO, H. Lavadora de louç $F$ FM - 304. Manual de instruções. São Paulo, s. n., 1985.

Recebido para publicação em 04.12 .93 